\title{
Statistical Optimization of Copper Oxide Nanoparticles Using Response Surface Methodology and Box-Behnken Design Towards In Vitro and In Vivo Toxicity Assessment
}

\author{
Santhoshkumar Jayakodi ${ }^{1}$ (D), Venkat Kumar Shanmugam 1 1,*(D) \\ 1 School of Biosciences and Technology, VIT University, Vellore - 632014, TN, India \\ * Correspondence: venkatkumars@ vit.ac.in;
}

Scopus Author ID 51462272000

Received: 6.09.2020; Revised: 22.09.2020; Accepted: 24.09.2020; Published: 26.09.2020

\begin{abstract}
The current study focusses on the optimization of Copper oxide nanoparticles (CuO NPs) biosynthesis with Alternanthera sessilis (L.) extract using response surface methodology (RSM). The effect of time, $\mathrm{pH}$, and extract to metal concentration ratio on the yield of synthesized nanoparticles (NPs) were estimated using Box-Behnken design. The influence of each of the parameters, as mentioned earlier, was determined by synthesizing nanoparticles under different conditions. A total of 29 experimental runs were carried out to estimate the crucial parameters. Extract to the metal ratio was found to be the vital parameter for yield optimization based on the p-values ( $p$-value $<0.05$ ). The physicochemical property of NPs, like size, was estimated to be in the range of 10-20 nm. In zebrafish, $48 \mathrm{hpf}$ and $72 \mathrm{hpf}$ were measured at $90 \mu \mathrm{M}$ to reduce dysfunction and mortality during organ development. These results can have a valuable impact on eco-toxicological effects.
\end{abstract}

Keywords: box-Behnken design; copper oxide NPs; Alternanthera sessilis; antioxidant; zebrafish.

(c) 2020 by the authors. This article is an open-access article distributed under the terms and conditions of the Creative Commons Attribution (CC BY) license (https://creativecommons.org/licenses/by/4.0/).

\section{Introduction}

Nano-biotechnology, a field that connects both nanotechnology and biotechnology, is dedicated to product improvement and technology creation. Nanoparticles are employed in the manufacture of several materials, including pigments, cosmetics, biomedical devices, etc [1,2]. Nanomaterials such as copper oxide nanoparticles are recently being employed in pharmaceutical fields, food packaging, and catalyst manufacturing [3,4]. Nanoparticles have been synthesized through numerous methods [5]; conventional strategies use toxic chemicals as reducing or stabilizing agents in order to prevent agglomeration. Also, $\mathrm{CuO}$ NPs, which is synthesized through chemical routes, are known to cause acute and chronic toxicity in aquatic organisms [6].

The reduction of copper chloride to copper oxide nanoparticles is carried out by the high content of diterpenoid lactones possessing polyol groups present in the Alternanthera sessilis (dwarf copper leaf) leaves at room temperature [7]. The importance of green chemistry has been raised in recent decades to prevent the usage of toxic materials [8]. Green synthesis or the biological method involves the use of plant extracts [9], microorganisms [10], and enzymes [11] is based on the principle of the utilization of non-toxic materials or environmentfriendly agents, which also deals with the diminished production of harmful substances [12]. However, there is inadequate evidence to prove the actual toxicity of nanomaterials. The nanotoxicology has focused on in vitro assays, using the variety of antioxidant systems. The 
advantage of this approach is that it considers the various level of physiological reactivity in the whole organism [13], and so, zebrafish (Danio rerio) has rapidly evolved as an ideal model organism for biotoxicity evaluation of nanomaterials. Zebrafish are used as a vertebrate model owing to its properties like small size, high fecundity, transparent embryos, rapid embryonic development cycle, and easy maintenance. Moreover, zebrafish resembles the human at gene metabolism level [14].

The toxicological studies on living organisms of nanoparticles suggested differential toxicities based on physiological properties like size, shape, agglomeration, concentration, dissolution, and application method [15]. Further, parameters such as morphology, concentration, and coating can also significantly contribute to its toxicity. In the present study, CuONPs were synthesized using Alternanthera sessilis leaf extract, a single-pot process, with no use of toxic chemicals or reagents. The optimized $\mathrm{AS}-\mathrm{CuO}$ was then used to evaluate the physicochemical and antioxidant activity. In vivo studies using embryonic and larval zebrafish model was used for evaluating the toxicological effects.

\section{Materials and Methods}

\subsection{Sample collection and preparation.}

The plant Alternanthera sessilis is available throughout tropical Africa, Australia, eastern and southern Asia. Fresh leaves of Alternanthera sessilis, free from diseases, were collected from VIT School of Agricultural Innovations and Advanced Learning (VAIAL). The plant was documented by the Plant anatomy research center, Chennai (Reference number: pg:191:1987) [16]. The fresh 250g of leaves was chopped, dipped into $100 \mathrm{~mL}$ of distilled water. The mixture was cooled and stored for experimental usage.

\subsection{Green synthesis of $\mathrm{CuO} N P$ s.}

To prepare $50 \mathrm{mM}$ of copper chloride solution, typically, $0.672 \mathrm{~g}$ was dissolved in 30 $\mathrm{mL}$ of aqueous extract. The solution was kept on an overnight shaker at $150 \mathrm{rpm}$. The aqueous extract was mixed with the copper chloride stock solution. The solution was kept for overnight shaking at $150 \mathrm{rpm}$. The formation of a deep green colored solution indicated a synthesis of $\mathrm{CuO}$ NPs Figure 1. The solution was transferred into a watch glass and heated at $80^{\circ} \mathrm{C}$ for 24 $\mathrm{h}$ resulting in black powder, which was further used for experimental analysis.

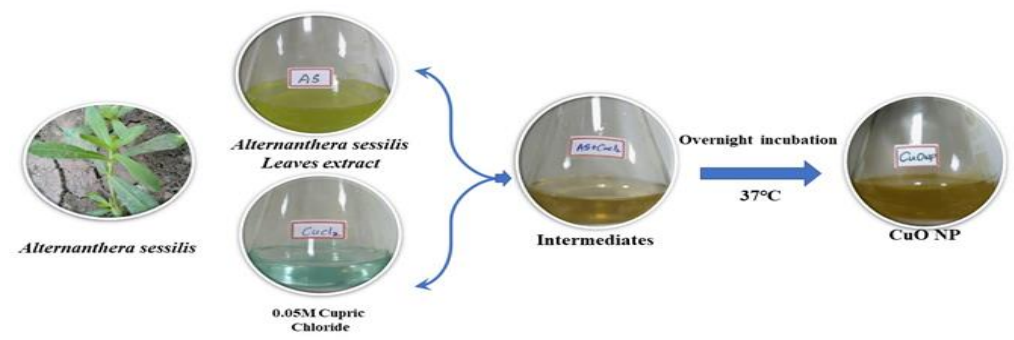

Figure 1. Schematic representation of the green synthesis of $\mathrm{CuO}$ NPs from the leaf extract of Alternanthera sessilis.

\subsection{Design of experiments and optimization.}

To optimize the process variables, thereby probing their relative or interactive effects on the synthesis of CuONPs, Box-Behnken design (BBD) was employed. It comprises three steps: (1) design of experimental sets and their execution, (2) regression-based response surface 
modeling, and (3) optimization and validation of the model. The effective process parameters which substantially contribute to the synthesis of CuONPs were investigated using statistical software called Design-Expert 11. Equation 1 was implemented to find out the number of experiments that would be required for the Box-Behnken design.

Where $\mathrm{k}$ and $\mathrm{C}_{0}$ refer to the number of experimental factors and central points, respectively, four experimental factors, which are independent, were subjected to analysis. The design created 29 experimental runs. The experimental parameters were denoted as A [Concentration of Copper Chloride mM $(25,50,75 \mathrm{mM})], \mathrm{B}$ [pH of reaction $(4,5,6)], \mathrm{C}$ [volume of Alternanthera sessilis in $\mathrm{mL}(20,30,40)$ ] and $\mathrm{D}$ [reaction time $(7,8,9 \mathrm{hrs})$ ] respectively and coded as $-1,0,1$ (low, central point, high. The relationship between these variables and its interactive responses was fitted using the below mentioned second-order polynomial quadratic equation. The two most crucial aspects, statistical significance, and proficiency of the experimental model, were determined with the help of analysis of variance (ANOVA). This statistical analysis was used in order to ensure that responses related to the levels of each variable could be categorized vigorously by enunciating the aforementioned equation, which had been fitted and represented as surface and contour plots.

\subsection{Physiochemical characterizations of $\mathrm{CuO} N P$ s.}

UV-Vis, DLS, FTIR, XRD, SEM with EDS were employed to understand the composition and physicochemical properties of $\mathrm{CuO}$ nanoparticles. The size of particles was estimated by SEM (Zeiss EVO18) attached to EDS and TEM. For SEM analysis, of CuO nanoparticles in solution were dried in a hot air oven, and images were captured at 10KV. The stability and size of $\mathrm{CuO}$ nanoparticles in the aqueous medium were estimated through zeta potential and hydrodynamic diameter measurement using DLS (HORIBA SZ100). UV-Visible spectra of $\mathrm{CuO}$ nanoparticles were obtained in the range of 200-600 $\mathrm{nm}$ at different time intervals using a double beam UV-Visible spectrophotometer (Cary 5000, Agilent, USA). XRD spectra were obtained in the $2 \theta^{\circ}$ range of $20^{\circ}$ to $80^{\circ}$ to comprehend the crystallinity and size of $\mathrm{CuO}$ nanoparticles using X-ray diffractometer (XRD Brukerd 8 Advance). FTIR spectroscopy, in the range of $400-4000 \mathrm{~cm}^{-1}$, was used to identify the compounds involved in the reduction and capping of nanoparticles.

\subsection{DPPH activity.}

A similar protocol was followed for the antioxidant activity of Magnolia champaca extracts mediated $\mathrm{CuO}$ nanoparticles was evaluated by the DPPH method [17]. Various concentrations of $\mathrm{CuO}$ nanoparticles $(100-500 \mu \mathrm{g} / \mathrm{ml})$ were mixed with a constant range of $(500 \mu \mathrm{l}) \mathrm{DPPH}$ solution. Finally, the solution was made with $3 \mathrm{~mL}$ of methanol. The same concentration of ascorbic acid was prepared used as a positive control. This entire mixture was shaken and for 30 min under the dark condition at room temperature. The absorbance was recorded at 517 .

$$
\text { Scavenging activity }(\%)=\text { control-test } / \text { control } \times 100
$$

\subsection{Radical ABTS radical scavenging assay.}

The in-vitro antioxidant activity of ABTS has formed. $2 \mathrm{mM}$ ABTS solution with 17 $\mathrm{mM},(0.3 \mathrm{ml})$ potassium persulfate was kept in the dark condition for $12-16 \mathrm{~h}$ at $28^{\circ} \mathrm{C}$. This 
solution was diluted in ethanol at $30^{\circ} \mathrm{C}$. Then, the ABTS solution was added to various concentrations of 100- $500 \mu \mathrm{g} / \mathrm{mL} \mathrm{CuO}$ nanoparticles and kept in the dark condition at room temperature for $30 \mathrm{~min}$. Ascorbic acid of the same concentration was used as a positive control. Absorbance was then measured at $734 \mathrm{~nm}$.

$$
\operatorname{ABTS}(\%)=\text { control-test } / \text { control } \times 100
$$

\subsection{Nitric oxide radical scavenging activity.}

Nitric oxide radical capturing analysis was calculated using the UV-Visible spectrophotometer method. Test samples at different concentrations $(100-500 \mu \mathrm{g} / \mathrm{mL})$ were dissolved in DMSO. $1 \mathrm{ml}$ of test solution was mixed with $1 \mathrm{ml}$ of sodium nitroprusside $(5 \mathrm{mM})$ in phosphate buffer saline and incubated at $25^{\circ} \mathrm{C}$ for $30 \mathrm{~min}$. Medium without a test solution was used as control. $1 \mathrm{ml}$ of Griess reagent was then added to an equal volume of incubated solution. The chromophore produced for the period of the diazotization of the nitrile with sulphanilamide was estimated at $546 \mathrm{~nm}$.

$$
\text { NO }(\%)=\text { control-test } / \text { control } \times 100
$$

\subsection{In-vivo toxicity of green synthesized $\mathrm{CuO} N P$ s on zebrafish.}

All experiments were performed according to relevant animal practice guidelines and regulations of OECD. Adult zebrafish were maintained at a temperature of $28.5^{\circ} \mathrm{C}$, with a $\mathrm{pH}$ of $7 \pm 0.2$, under 14:10 h light / dark photoperiod. They were given live salt shrimp once a day and dry meals twice a day. A natural random mating procedure was used to obtain zebrafish embryos, which were further raised in embryonic water $(0.2 \mathrm{~g} / \mathrm{L}$ saline in double-distilled water) at $28.5^{\circ} \mathrm{C}$. Zebrafish fertilized eggs were stored at $24 \pm 3^{\circ} \mathrm{C}$ until hatching. The morphological changes and developments were monitored using microscopy. The rate of hatching was determined by hatching 72 hpf compared to the untreated group of multiple embryos. Mortality was depicted as many dead embryos after $72 \mathrm{hpf}$ compared with the group that was left untreated. The experiment was performed thrice.

\subsection{Zebrafish embryotoxicity (mortality and hatchability).}

Disclosures were conducted with minor modifications following OECD Guideline 236 (OECD, 2013). Briefly, fertilized zebrafish embryos ( $<6 \mathrm{hpf})$ were tested for viability, and healthy embryos were collected for estimating the mortality and hatchability in almost equivalent growth conditions. Tested for each sample used different concentrations at 30,60, 90,120 , and $150 \mu \mathrm{M}$. Mortality and hatching were observed during the exposure period of 5 days under extreme care. The mortality was recorded after 1, 2, 3, 4 days of the incubation period, and the percentage of mobility was reported. The success of the hatching process was confirmed after $96 \mathrm{~h}$ of hatching.

\subsection{Statistical analyses.}

All results are represented as the mean for experiments repeated in triplicated and presented with standard deviation. Statistical analysis of the results was carried out by using Graph pad 6.1 software package and considered significant at $<0.05 \mathrm{p}$ values. 


\section{Results and Discussion}

\subsection{Design of experiments and optimization.}

The regression equation, which was represented graphically using the threedimensional response surface plots and the corresponding contour plots. Figure 2a. Shows the contour plot of two factors (volume of Andrographis paniculate extract and amount of copper nitrate), while Figure $2 \mathrm{~b}$ shows the corresponding 3D surface plot for the $\mathrm{CuO}$ NPs yield. Table 1 contains the list of experimental runs and the similar responses obtained from the experiments projected by BBD. A regression coefficient R2 value of 0.9802 was obtained with a secondorder quadratic equation generated for the green synthesis of $\mathrm{CuO}$ NPs.

The statistical significance of the model was ascertained based on the results obtained from the analysis of variance. As observed from the results, the model F-value was 49.47, which implied that the model was significant. The predicted R2 (0.8886) was found to agree with the adjusted R2, which was calculated to be 0.9604 . The computed value of C.V\% was found to be 2.63, which is relatively low, indicating greater accuracy and consistency of the model.

The adequacy of the model was evaluated using the residuals from the least-squares fit as a tool. The quadratic model generated using the response surface result was found to be significant as the $\mathrm{p}$-value is $<0.0001$. The standard probability plot was plotted to assess the normality assumptions. It suggests that the assumptions made are agreeable based on the fact that the extra points cluster along the diagonal line. The value of the absorbance generated by performing the experiments, and the corresponding values predicted by the statistical model Figure 3, which relate to the amount of $\mathrm{CuO}$ NPs being synthesized, were compared. The results (A) Copper Chloride $50 \mathrm{mM}$, (B) PH of reaction 5, (C) Alternanthera sessilis in $30 \mathrm{~mL}$, and (D) reaction time of $8 \mathrm{hrs}$ indicate that the empirical model is considerably on a par with the experimental one within the given innovative ranges.
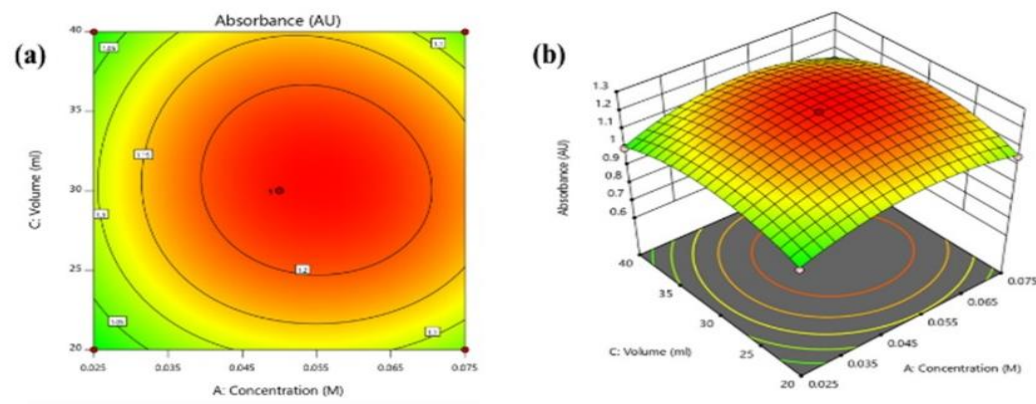

Figure 2. (a) 2 D Contour plot (b) 3D surface plot of absorbance versus concentration of copper chloride and volume of Alternanthera sessilis.
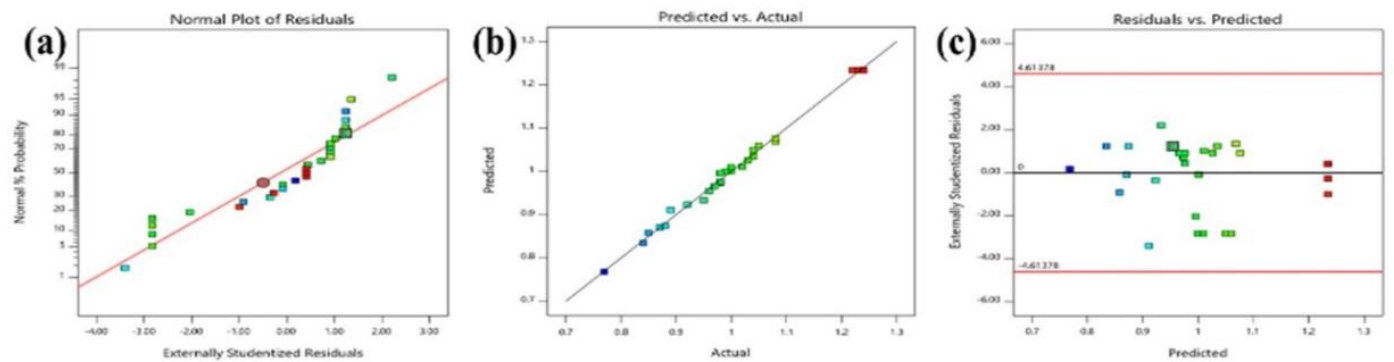

Figure 3. (a) Normal plot for residuals (b) predicted versus actual plot (c) residual versus predicted plot for the biosynthesis of $\mathrm{CuO}$ NPs model. 


\subsection{Validation of the statistical model.}

To establish the significance and to further adequacy of the generated models for maximization of the yield nanoparticles, the experiment was repeated using variable levels suggested by the optimum model, and size was calculated (Table 2). The size of the synthesized $\mathrm{CuO}$ NPs was $9.55 \mathrm{~nm}$, which was further confirmed by the data generated using the statistical tool. The results emphasized the effectiveness of RSM in experimental design for optimizing the process parameters and in projecting the prominence of both the individual and interactive paraphernalia of the experimental variables in nanoparticle synthesis.

\subsection{UV-Vis Spectra studies.}

UV-Vis spectra indicated the synthesis of shape and size-controlled nanoparticles. Visual color change from green to greyish black suggests the synthesis of $\mathrm{CuO}$ NPs with the use of Alternanthera sessilis extract Figure 1 represents the synthesis. Surface Plasmon Resonance (SPR) is an optical property exhibited by noble metal nanoparticles upon interaction with resonant light. The change in color is attributed to the excitation of surface plasma vibrations (SPR) in the presence of metal nanoparticles [18]. The absorbance maxima peak demonstrates the presence of CuO NPs as CuO SPR bands are centered between 335 and 400 nm Figure 4.

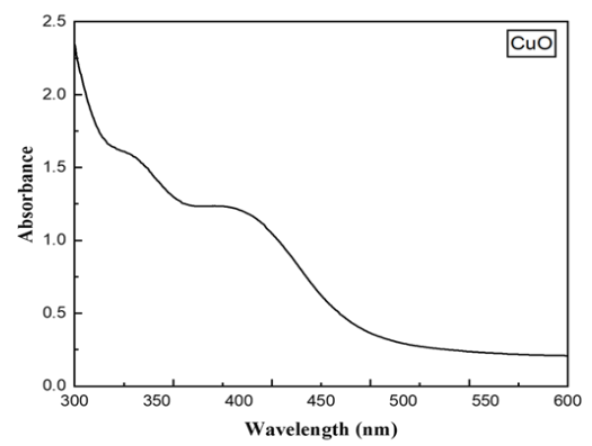

Figure 4. UV-Vis spectra of synthesized CuO NPs.

\subsection{Size and shape determination of $\mathrm{CuO}$ nanoparticles.}

HRTEM and SEM are the most powerful analytical tools available, providing information on the morphology of the synthesized $\mathrm{CuO}$ NPs.

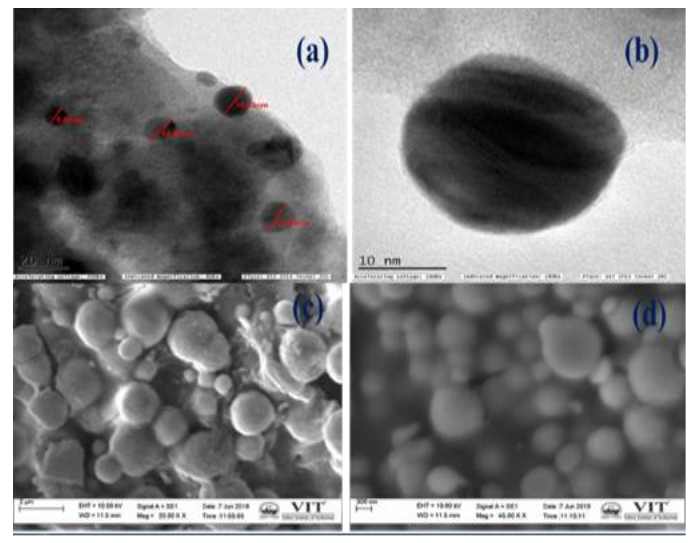

Figure 5. Electron micrographs of green synthesized CuO NPs. (a) TEM (Scale bar of $20 \mathrm{~nm}$ ). (b) Magnified view of TEM (scale bar $10 \mathrm{~nm}$ ). (c) SEM (Scale bar of $2 \mu \mathrm{m}$ ). (d) Magnified view of SEM (scale bar $300 \mathrm{~nm}$ ). 
Particles were confirmed to be spherical with a uniform diameter (10-20 nm) using HRTEM Figure $5 \mathrm{a}-\mathrm{b}$ and SEM Figure $5 \mathrm{c}$-d. EDS analysis confirmed the purity of CuO NPs by $57.81 \%(\mathrm{Cu})$ and $34.07 \%(\mathrm{O})$ weight percent. However, a small amount of chloride was also found in the EDS spectra Figure 6. HRTEM image reveals capping of CuO NPs with a thickness of $20 \mathrm{~nm}$, which could be attributed to the organic compounds of the leaf. Previous studies report the interaction of secondary metabolites with metal and metal oxide nanoparticles [19].

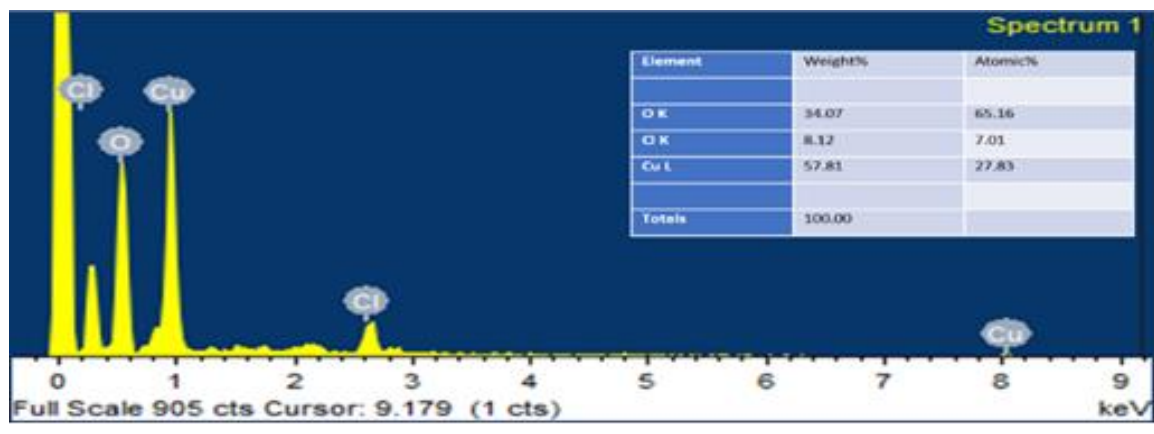

Figure 6. EDS analysis of $\mathrm{CuO}$ NPs.

\subsection{DLS and Zeta analysis of $\mathrm{CuO} N P$ s.}

The stability of nanoparticles is essential for medicinal applications. Interactions occurring in nanoparticle solution include the intramolecular interaction among nanoparticles, and intermolecular interactions of nanoparticles with the surrounding fluid eventually results in nanoparticles agglomeration [20]. The high zeta potential value represents nanoparticles stability in an aqueous medium Figure 7 . The Zeta potential value of $-18 \mathrm{mV}$ indicates excellent colloidal stability.

DLS is a potent technique for monitoring the size of nanoparticles and estimating their colloidal stability [21]. DLS is commonly employed to estimate the hydrodynamic diameter of $\mathrm{CuO}$ NPs. The hydrodynamic diameter of $\mathrm{CuO}$ NPs was determined to be $80.2 \mathrm{~nm}$ using DLS Figure 8.

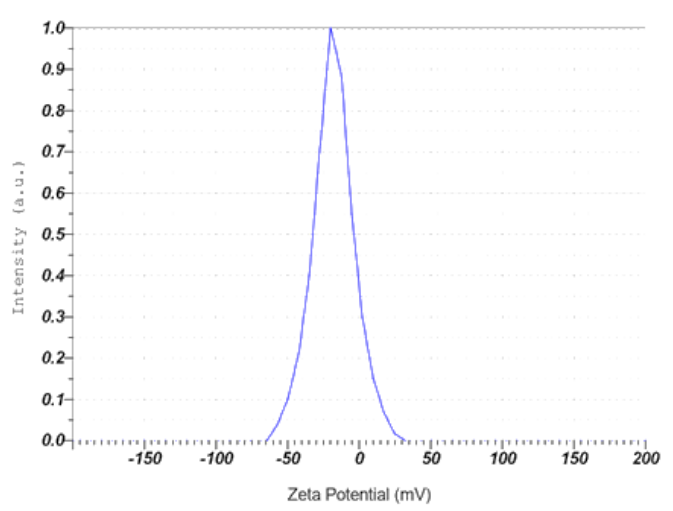

Figure 7. Zeta potential measurement of green synthesized $\mathrm{CuO}$ NPs.

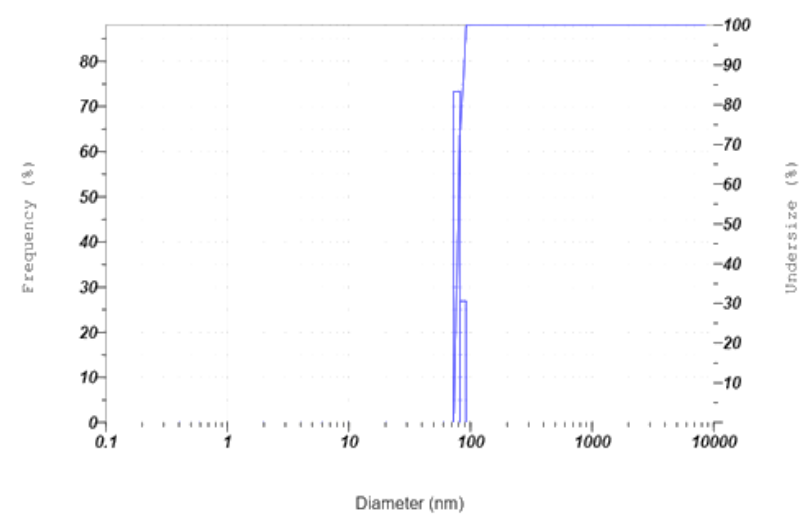

Figure 8. Particle size of $\mathrm{CuO}$ NPs measured by Dynamic light scattering.

\subsection{FTIR and XRD analysis of biosynthesized $\mathrm{CuO} N P$ s.}

FTIR spectra revealed the presence of biomolecules in Alternanthera sessilis extract potential responsible for capping, reduction, and stabilization of $\mathrm{CuO}$ NPs. FTIR spectra of Alternanthera sessilis (AS) extract and dried $\mathrm{CuO}$ NPs are depicted in Figure 9A-B. Previous 
literature suggests the role of tannins, carbohydrates, proteins, and ascorbic acid from the Alternanthera sessilis extract in synthesis and capping of Ag NPs [22]. These secondary metabolites are known to possess antioxidant, anti-inflammatory potentials [23]. FTIR spectra of AS reveals the presence of broad -OH stretching vibration at $2945.30 \mathrm{~cm}^{-1}$ and cellulose at $3313.71 \mathrm{~cm}^{-1}$. Other bands at $2833.43 \mathrm{~cm}^{-1}, 1658.78 \mathrm{~cm}^{-1}, 1413.82 \mathrm{~cm}^{-1}, 1112.93 \mathrm{~cm}^{-1}, 1024.20$ $\mathrm{cm}^{-1}$ are attributed to the stretching vibration of alkane, stretching vibration of aromatic compounds, ketone, carboxylic acid [24], and C-N stretching vibrations of aromatic nitro compounds [25]. , The presence of similar bands in the FTIR spectra of CuO NPs, suggests the involvement of Alternanthera sessilis extract in the synthesis and reduction of nanoparticles. FTIR spectra of $\mathrm{CuO}$ NPs indicates the presence of bands at $3439.08 \mathrm{~cm}^{-1}, 3331.07 \mathrm{~cm}^{-1}$, $1622.13 \mathrm{~cm}^{-1}, 1396.46 \mathrm{~cm}^{-1}, 1078.21 \mathrm{~cm}^{-1}, 802.39 \mathrm{~cm}^{-1}$ and $580.57 \mathrm{~cm}^{-1}$ corresponding to O-H bond stretching vibration, $-\mathrm{NH} 2$ stretching vibration of amino acid salts, $\mathrm{C}=\mathrm{N}$ stretching vibration of conjugated cyclic oximes/imines, $\mathrm{C}-\mathrm{H}$ vibration, $\mathrm{C}-\mathrm{O}$ stretching vibration of alcohols, CH3-metal groups and CS2 stretching vibration. Results were similar to previous literature [26].

The X-ray diffraction pattern of the synthesized CuO NPs is depicted in Figure 10. XRD peaks were indexed using the standard peak values available in JCPDS files (JCPDS card no.: 89-5895) [24,27]. The position and relative intensities of all eleven diffraction peaks were well consistent with the standard XRD pattern of $\mathrm{CuO}$. Some of the characteristics peaks are observed at $2 \theta$ angles of $32.82^{\circ}, 35.83^{\circ}, 39.04^{\circ}, 49.21^{\circ}, 53.49^{\circ}, 58.71^{\circ}, 62.05^{\circ}, 66.47^{\circ}, 68.47^{\circ}$, $72.62^{\circ}, 75.16^{\circ}$ and are assigned respectively to the (110), (111), (200), (202), (020), (202), (113), (022), (113), (311), and (004) diffraction planes. The XRD pattern revealed the formation of $\mathrm{CuO}$ NPs with a monoclinic structure. The average size of the synthesized nanoparticles was observed to be $17.28 \mathrm{~nm}$.

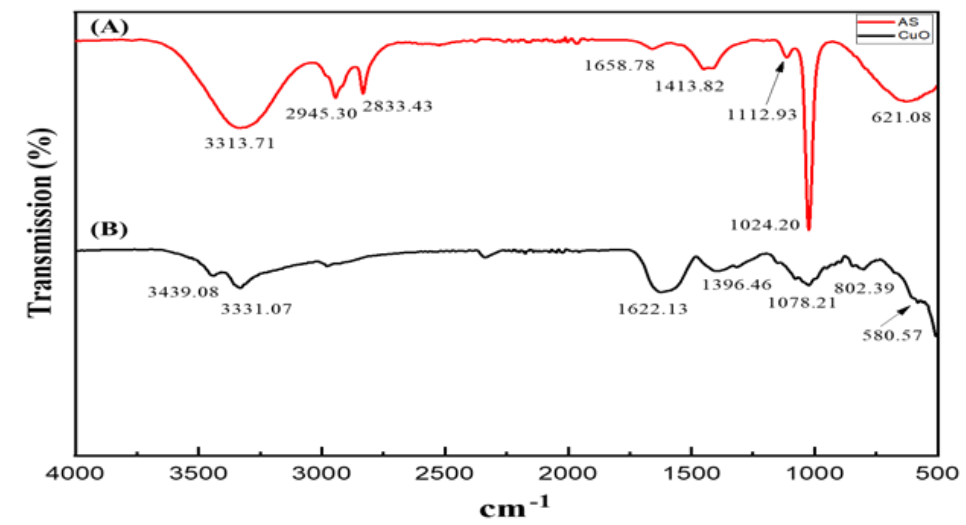

Figure 9. FT-IR spectrum of (A) Alternanthera sessilis (B) CuO NPs.

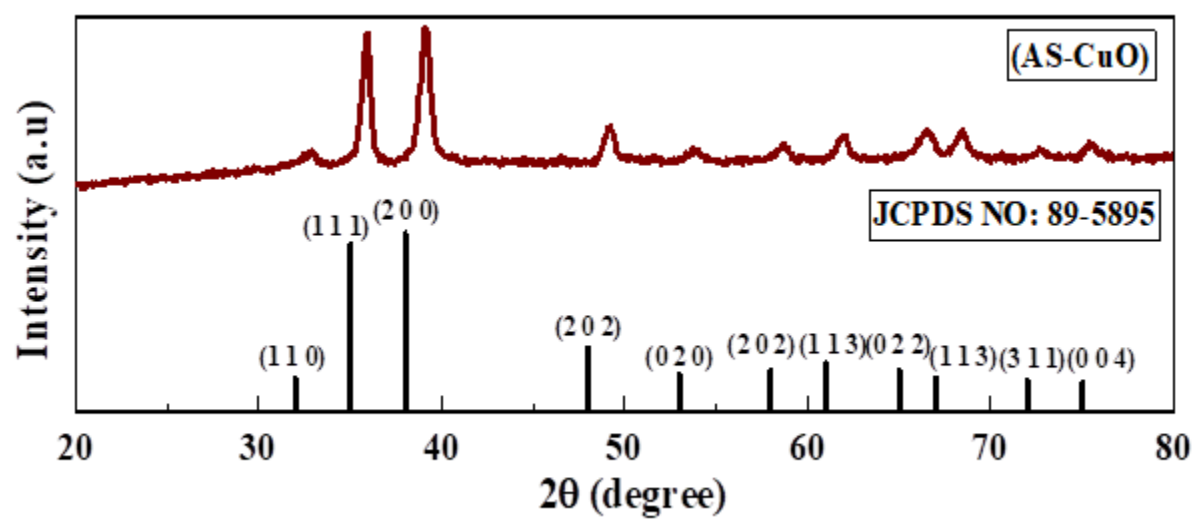

Figure 10. X-ray diffraction pattern of $\mathrm{CuO}$ NPs. 


\subsection{Antioxidant activity.}

The DPPH radical scavenging assay of $\mathrm{CuO}$ NPs at different concentrations is shown in Figure 11a. The results revealed dose-dependent \% inhibition of $27.27 \%$ at $100 \mu \mathrm{g} / \mathrm{mL}$, $39.81 \%$ at $200 \mu \mathrm{g} / \mathrm{mL}, 61.89 \%$ at $300 \mu \mathrm{g} / \mathrm{mL}, 74.97 \%$ at $400 \mu \mathrm{g} / \mathrm{mL}, 84.63 \%$ at $500 \mu \mathrm{g} / \mathrm{mL}$ respectively. $\mathrm{CuO}$ NPs demonstrated significant radical scavenging activity when compared to ascorbic acid. Phytochemicals present in the Alternanthera sessilis might have contributed to the high antioxidant potential of $\mathrm{CuO}$ NPs [28]. The ABTS radical scavenging assay of the synthesized CuO NPs is shown in Figure 11b. At $500 \mu \mathrm{g} / \mathrm{mL}$ concentration, the inhibition of $\mathrm{CuO}$ NPs was found to be $71.02 \%$, and that of the standard was $66.46 \%$. The result shows dose-dependent $\%$ inhibition of $16.24 \%$ at $100 \mu \mathrm{g} / \mathrm{mL}, 40.02 \%$ at $200 \mu \mathrm{g} / \mathrm{mL}, 54.30 \%$ at 300 $\mu \mathrm{g} / \mathrm{mL}, 62.03 \%$ at $400 \mu \mathrm{g} / \mathrm{mL}, 71.02 \%$ at $500 \mu \mathrm{g} / \mathrm{mL}$. The NO radical scavenging assay of the synthesized $\mathrm{CuO}$ NPs is sown in Figure 11c. The results demonstrate \% inhibition of $25.55 \%$ at $100 \mu \mathrm{g} / \mathrm{mL}, 45.16 \%$ at $200 \mu \mathrm{g} / \mathrm{mL}, 58.44 \%$ at $300 \mu \mathrm{g} / \mathrm{mL}, 75.48 \%$ at $400 \mu \mathrm{g} / \mathrm{mL}, 82.68 \%$ at $500 \mu \mathrm{g} / \mathrm{mL}$. The results suggested that the synthesized $\mathrm{CuO}$ NPs have moderate antioxidant activity against ABTS and NO radical scavenging assays. The hydroxyl group of plant phenolic compounds show scavenging potential and, thus, can be a contributor to the antioxidant activity of $\mathrm{CuO}$ NPs [29].

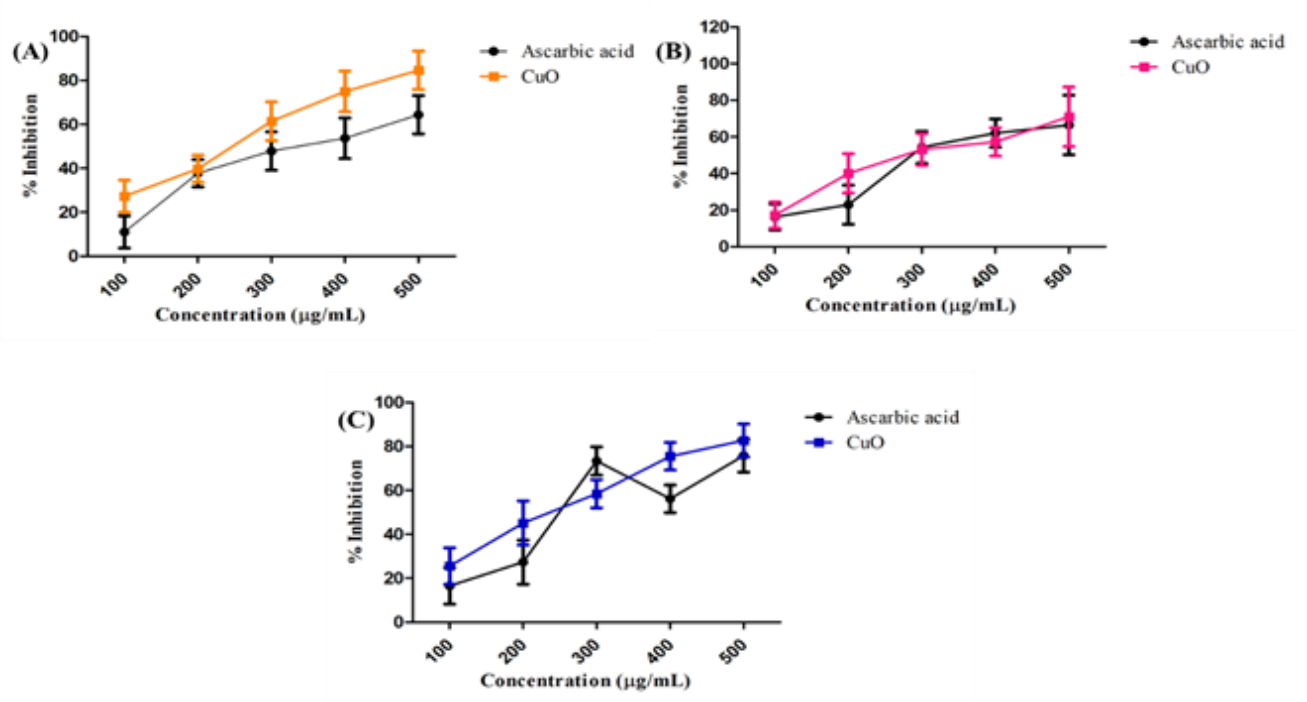

Figure 11. In vitro antioxidant activity of copper oxide nanoparticles using (A) DPPH assay (B) ABTS assay, and (C) NO assay.

\subsection{In vivo toxicity of green synthesized $\mathrm{CuO}$ Nanoparticles in zebrafish embryos.}

Rate of hatching and viability was considered to be viral parameters to evaluate the toxicity of $\mathrm{CuO}$ NPs on Zebrafish embryonic development [30]. The mortality rate of zebrafish embryos was high in $\mathrm{CuO}$ NPs treated embryo when compared to the AS-CuO treated one. Compared with the $\mathrm{AS}-\mathrm{CuO}$ groups, the mortality rate was estimated to be 5 times more in $\mathrm{CuO}$ treated groups at a concentration of $120 \mu \mathrm{M}$. The hatching rates of zebrafish embryos after the $\mathrm{CuO}$ NPs treatments were given in Figure 12A. As shown in Figure 12B, control groups and the $\mathrm{CuO}$ NPs treated embryos started to hatch at $48 \mathrm{hpf}$. A dose-dependent decrease in the hatching rate decreased significantly was observed between 48 and 72 hpf [31]. As compared to the AS-CuO group, the hatching rate in the highest concentration $(150 \mu \mathrm{M}$ AS$\mathrm{CuO}$ ) group was decreased by about $30 \%$. The highest body malformation rate was found for the highest concentration of $\mathrm{CuO} N$ Ps treatment $(150 \mu \mathrm{M})$ Figure $12 \mathrm{C}$. 

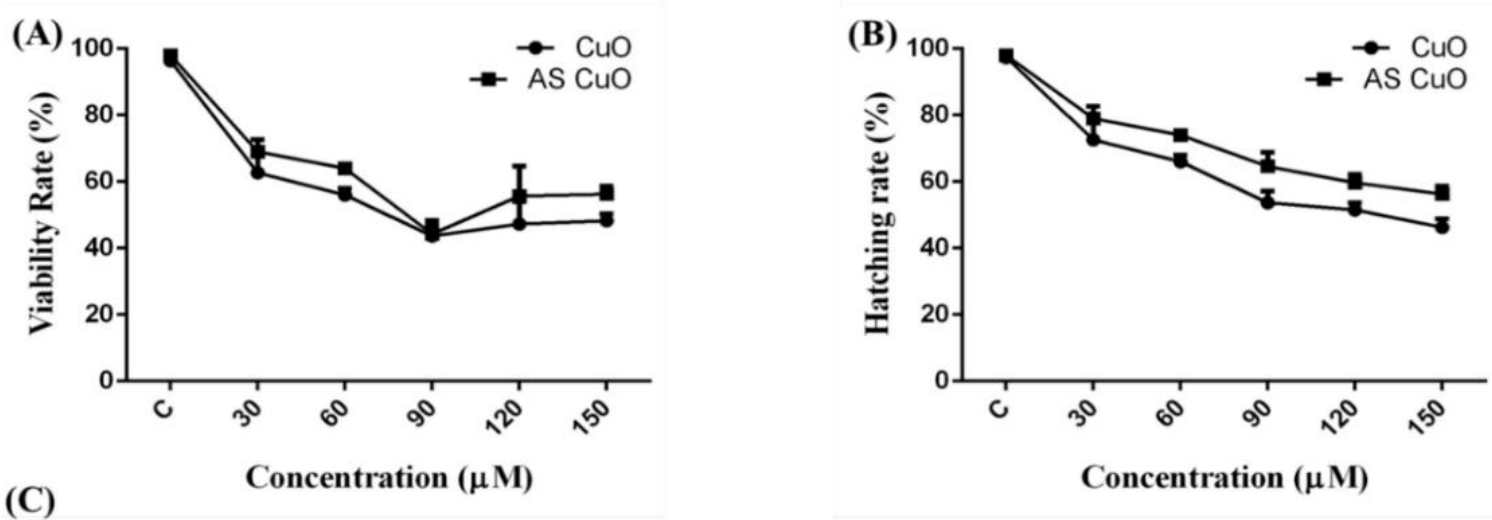

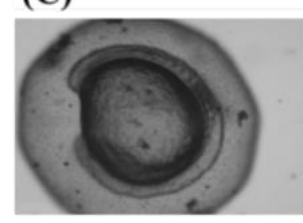

$4 \mathrm{hpf}$

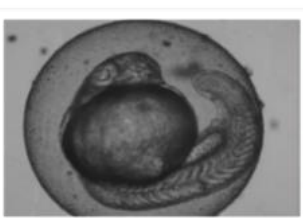

$24 \mathrm{hpf}$

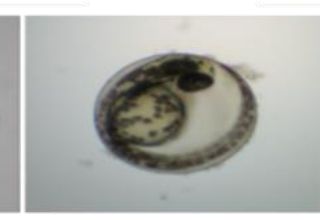

48 hpf

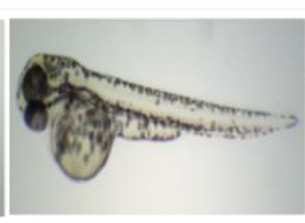

72 hpf

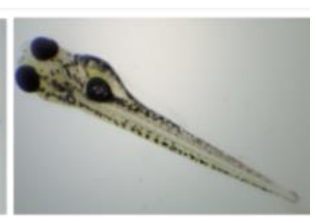

$96 \mathrm{hpf}$

Figure 12. Zebrafish embryo viability, hatchability, and embryo development.

Table 1. Experimental matrix and responses (absorbance) for Box-Behnken design.

\begin{tabular}{|c|c|c|c|c|c|}
\hline \multirow{3}{*}{ Run } & Factor 1 & Factor 2 & Factor 3 & Factor 4 & Response \\
\hline & A: Concentration & B: pH & C: Volume & D: Time & Absorbance \\
\hline & $\mathbf{M}$ & & ml & hrs & a. $\mathbf{u}$ \\
\hline 1 & 0.05 & 6 & 30 & 7 & 0.77 \\
\hline 16 & 0.075 & 6 & 30 & 8 & 0.84 \\
\hline 8 & 0.05 & 6 & 40 & 8 & 0.85 \\
\hline 14 & 0.05 & 6 & 20 & 8 & 0.87 \\
\hline 12 & 0.025 & 6 & 30 & 8 & 0.88 \\
\hline 20 & 0.05 & 4 & 30 & 9 & 0.89 \\
\hline 6 & 0.05 & 6 & 30 & 9 & 0.92 \\
\hline 9 & 0.05 & 4 & 20 & 8 & 0.95 \\
\hline 4 & 0.025 & 4 & 30 & 8 & 0.96 \\
\hline 2 & 0.025 & 5 & 30 & 9 & 0.97 \\
\hline 3 & 0.05 & 4 & 30 & 7 & 0.98 \\
\hline 21 & 0.05 & 5 & 20 & 9 & 0.98 \\
\hline 24 & 0.05 & 5 & 40 & 7 & 0.98 \\
\hline 25 & 0.025 & 5 & 30 & 7 & 0.98 \\
\hline 22 & 0.025 & 5 & 20 & 8 & 0.99 \\
\hline 5 & 0.05 & 5 & 20 & 7 & 1 \\
\hline 15 & 0.025 & 5 & 40 & 8 & 1 \\
\hline 27 & 0.05 & 4 & 40 & 8 & 1.02 \\
\hline 13 & 0.075 & 5 & 30 & 7 & 1.03 \\
\hline 7 & 0.075 & 4 & 30 & 8 & 1.04 \\
\hline 29 & 0.075 & 5 & 40 & 8 & 1.04 \\
\hline 10 & 0.075 & 5 & 20 & 8 & 1.05 \\
\hline 11 & 0.075 & 5 & 30 & 9 & 1.08 \\
\hline 28 & 0.05 & 5 & 40 & 9 & 1.08 \\
\hline 17 & 0.05 & 5 & 30 & 8 & 1.22 \\
\hline 19 & 0.05 & 5 & 30 & 8 & 1.23 \\
\hline 18 & 0.05 & 5 & 30 & 8 & 1.24 \\
\hline 23 & 0.05 & 5 & 30 & 8 & 1.24 \\
\hline 26 & 0.05 & 5 & 30 & 8 & 1.24 \\
\hline
\end{tabular}

Table 2. Results of validation experiments.

\begin{tabular}{l|l} 
Number of runs & Absorbance at $\mathbf{4 0 0} \mathbf{~ n m}$ \\
\hline $\mathbf{1}$ & 1.22 \\
\hline $\mathbf{2}$ & 1.24 \\
\hline $\mathbf{3}$ & 1.24 \\
\hline Average & 1.23 \\
\hline Predicted & 1.27
\end{tabular}




\section{Conclusions}

In the present study, the biosynthesis of $\mathrm{CuO}$ NPs was attempted using greener techniques by optimizing all crucial parameters using statistical designs. The presence of $\mathrm{CuO}$ in the synthesized nanoparticle was confirmed using UV-Vis spectrophotometry, FTIR, EDS, and XRD techniques. The morphology and the size of CuO NPs were determined by SEM and TEM studies. In summary, successful green synthesis of stable, well-characterized $\mathrm{CuO}$ nanoparticle was carried out, the in vitro and in vivo toxic impact was investigated with comparison to commercially available CuO NPs. Data from this report suggested a novel method of green synthesis of $\mathrm{CuO}$ nanoparticles.

\section{Funding}

This research received no external funding.

\section{Acknowledgments}

The authors thank the Vellore Institute of Technology, Vellore, for providing "VIT SEED GRANT" for carrying out this research work.

\section{Conflicts of Interest}

The authors declare no conflict of interest.

\section{References}

1. Zhang, X.; Zhang, N.; Zhou, Y.; Delatolla, R.; Song, Y.; Ma, Y.; Zhang, H.; Zhang, X.; Zhang, N.; Zhou, $\mathrm{Y}$. Insight on the microbial activity and microbiome in partial nitrification systems: $\mathrm{CuO}$ nanoparticles impact under different $\mathrm{pH}$ levels. Environmental Engineering Research 2020, 25, 960-968, https://doi.org/10.4491/eer.2019.425

2. Molinari, S.; Magro, M.; Baratella, D.; Salviulo, G.; Ugolotti, J.; Filip, J.; Petr, M.; Tucek, J.; Zoppellaro, G.; Zboril, R. Smart synthetic maghemite nanoparticles with unique surface properties encode binding specificity toward AsIII. Science of The Total Environment 2020, 741, https://doi.org/10.1016/j.scitotenv.2020.140175

3. Wang, Y.; Zhou, J.; Liu, L.; Huang, C.; Zhou, D.; Fu, L. Characterization and toxicology evaluation of chitosan nanoparticles on the embryonic development of zebrafish, Danio rerio. Carbohydrate polymers 2016, 141, 204-210, DOI: https://doi.org/10.1016/j.carbpol.2016.01.012.

4. Souri, M.; Hoseinpour, V.; Shakeri, A.; Ghaemi, N. Optimisation of green synthesis of MnO nanoparticles via utilising response surface methodology. IET nanobiotechnology 2018, 12, 822-827, https://doi.org/10.1049/iet-nbt.2017.0145.

5. Ma, X.; Sheikholeslami, M.; Jafaryar, M.; Shafee, A.; Nguyen-Thoi, T.; Li, Z. Solidification inside a clean energy storage unit utilizing phase change material with copper oxide nanoparticles. Journal of Cleaner Production 2020, 245, https://doi.org/10.1016/j.jclepro.2019.118888.

6. Vale, G.; Mehennaoui, K.; Cambier, S.; Libralato, G.; Jomini, S.; Domingos, R.F. Manufactured nanoparticles in the aquatic environment-biochemical responses on freshwater organisms: a critical overview. Aquatic Toxicology 2016, 170, 162-174, https://doi.org/10.1016/j.aquatox.2015.11.019.

7. Firdhouse, M.J.; Lalitha, P. Biosynthesis of silver nanoparticles using the extract of Alternanthera sessilisantiproliferative effect against prostate cancer cells. Cancer nanotechnology 2013, 4, 137-143, https://doi.org/10.1007/s12645-013-0045-4.

8. Sackey, J.; Nwanya, A.; Bashir, A.; Matinise, N.; Ngilirabanga, J.; Ameh, A.; Coetsee, E.; Maaza, M. Electrochemical properties of Euphorbia pulcherrima mediated copper oxide nanoparticles. Materials Chemistry and Physics 2020, 244, https://doi.org/10.1016/j.matchemphys.2020.122714.

9. Giannousi, K.; Avramidis, I.; Dendrinou-Samara, C. Synthesis, characterization and evaluation of copper based nanoparticles as agrochemicals against Phytophthora infestans. RSC Advances 2013, 3, 21743-21752, https://doi.org/10.1039/C3RA42118J.

10. Azam, A.; Ahmed, A.S.; Oves, M.; Khan, M.S.; Habib, S.S.; Memic, A. Antimicrobial activity of metal oxide nanoparticles against Gram-positive and Gram-negative bacteria: a comparative study. International journal of nanomedicine 2012, 7, 6003, doi: 10.2147/IJN.S35347. 
11. Luo, J.; Jiang, S.; Zhang, H.; Jiang, J.; Liu, X. A novel non-enzymatic glucose sensor based on Cu nanoparticle modified graphene sheets electrode. Analytica chimica acta 2012, 709, 47-53, https://doi.org/10.1016/j.aca.2011.10.025.

12. Hussain, M.A.; Shah, A.; Jantan, I.; Tahir, M.N.; Shah, M.R.; Ahmed, R.; Bukhari, S.N.A. One pot light assisted green synthesis, storage and antimicrobial activity of dextran stabilized silver nanoparticles. Journal of nanobiotechnology 2014, 12, https://doi.org/10.1186/s12951-014-0053-5

13. Spitsbergen, J.M.; Tsai, H.-W.; Reddy, A.; Miller, T.; Arbogast, D.; Hendricks, J.D.; Bailey, G. Neoplasia in zebrafish (Danio rerio) treated with 7, 12-Diniethylbenz [a] anthracene by two exposure routes at different developmental stages. Toxicologic $\quad$ Pathology $2000, \quad$ 2000, https://doi.org/10.1177/019262330002800511.

14. Sun, G.; Liu, K. Developmental toxicity and cardiac effects of butyl benzyl phthalate in zebrafish embryos. Aquatic toxicology 2017, 192, 165-170, https://doi.org/10.1016/j.aquatox.2017.09.020.

15. Samei, M.; Sarrafzadeh, M.-H.; Faramarzi, M.A. The impact of morphology and size of zinc oxide nanoparticles on its toxicity to the freshwater microalga, Raphidocelis subcapitata. Environmental Science and Pollution Research 2019, 26, 2409-2420, https://doi.org/10.1007/s11356-018-3787-z.

16. Nair, N. Flora of Tamil Nadu, India: Analysis. Botanical Survey of India, Department of Environment: Volume 2, 1987.

17. Thanigaivel, S.; Hindu, S.V.; Vijayakumar, S.; Mukherjee, A.; Chandrasekaran, N.; Thomas, J. Differential solvent extraction of two seaweeds and their efficacy in controlling Aeromonas salmonicida infection in Oreochromis mossambicus: a novel therapeutic approach. Aquaculture 2015, 443, 56-64, https://doi.org/10.1016/j.aquaculture.2015.03.010.

18. Mali, S.C.; Raj, S.; Trivedi, R. Biosynthesis of copper oxide nanoparticles using Enicostemma axillare (Lam.) leaf extract. Biochemistry and biophysics reports 2019, 20, https://doi.org/10.1016/j.bbrep.2019.100699

19. Dimkpa, C.O.; Zeng, J.; McLean, J.E.; Britt, D.W.; Zhan, J.; Anderson, A.J. Production of indole-3-acetic acid via the indole-3-acetamide pathway in the plant-beneficial bacterium Pseudomonas chlororaphis O6 is inhibited by $\mathrm{ZnO}$ nanoparticles but enhanced by $\mathrm{CuO}$ nanoparticles. Appl. Environ. Microbiol. 2012, 78, 1404-1410, https://doi.org/10.1128/AEM.07424-11.

20. Sokhal, G.S.; Gangacharyulu, D.; Bulasara, V.K. Influence of copper oxide nanoparticles on the thermophysical properties and performance of flat tube of vehicle cooling system. Vacuum 2018, 157, 268276, https://doi.org/10.1016/j.vacuum.2018.08.048.

21. Anand, M.A.V.; Saravanakumar, K.; Anbazhagan, S.; Venkatachalam, K.; Wang, M.-H. Folic acid functionalized starch encapsulated green synthesized copper oxide nanoparticles for targeted drug delivery in breast cancer therapy. International Journal of Biological Macromolecules 2020, 164, 2073-2084, https://doi.org/10.1016/j.ijbiomac.2020.08.036

22. Niraimathi, K.; Sudha, V.; Lavanya, R.; Brindha, P. Biosynthesis of silver nanoparticles using Alternanthera sessilis (Linn.) extract and their antimicrobial, antioxidant activities. Colloids and Surfaces B: Biointerfaces 2013, 102, 288-291, https://doi.org/10.1016/j.colsurfb.2012.08.041.

23. Tiwari, R.; Tripathi, T.; Khan, Y.A.; Gupta, A.; Dhobi, M.; Srivastava, S.; Singh, B.; Shanker, K.; Kalaiselvan, V.; Singh, G.N. Metabolite Profiling, Isolation of Cyclic Polyols, Antioxidant and Antiinflammatory Activities of Aegle Marmelos: NMR and GC-MS Based Metabolomics Study. Journal of Herbs, Spices \& Medicinal Plants 2020, 1-15, https://doi.org/10.1080/10496475.2020.1786873.

24. Ramzan, M.; Obodo, R.M.; Mukhtar, S.; Ilyas, S.; Aziz, F.; Thovhogi, N. Green synthesis of copper oxide nanoparticles using Cedrus deodara aqueous extract for antibacterial activity. Materials Today: Proceedings 2020, https://doi.org/10.1016/j.matpr.2020.05.472.

25. Inaoka, S.; Iwata, K.; Saha, S. Towards the critical understanding of selected vibrational features in biologically important dicyano aromatic conjugated molecules: Importance of electron donating/withdrawal groups and geometry associated with dicyano group. Spectrochimica Acta Part A: Molecular and Biomolecular Spectroscopy 2020, 224, 117419, https://doi.org/10.1016/j.saa.2019.117419.

26. Kumari, P.; Panda, P.K.; Jha, E.; Kumari, K.; Nisha, K.; Mallick, M.A.; Verma, S.K. Mechanistic insight to ROS and apoptosis regulated cytotoxicity inferred by green synthesized $\mathrm{CuO}$ nanoparticles from Calotropis gigantea to embryonic zebrafish. Scientific reports 2017, 7, https://doi.org/10.1038/s41598-017-16581-1

27. Mohamed, E.A. Green synthesis of copper \& copper oxide nanoparticles using the extract of seedless dates. Heliyon 2020, 6, https://doi.org/10.1016/j.heliyon.2019.e03123

28. Othman, A.; Ismail, A.; Hassan, F.A.; Yusof, B.N.M.; Khatib, A. Comparative evaluation of nutritional compositions, antioxidant capacities, and phenolic compounds of red and green sessile joyweed (Alternanthera sessilis). Journal of Functional Foods 2016, 21, 263-271, https://doi.org/10.1016/j.jff.2015.12.014

29. Sarkar, J.; Chakraborty, N.; Chatterjee, A.; Bhattacharjee, A.; Dasgupta, D.; Acharya, K. Green Synthesized Copper Oxide Nanoparticles Ameliorate Defence and Antioxidant Enzymes in Lens culinaris. Nanomaterials 2020, 10, https://doi.org/10.3390/nano10020312. 
30. Boyle, D.; Clark, N.J.; Handy, R.D. Toxicities of copper oxide nanomaterial and copper sulphate in early life stage zebrafish: Effects of $\mathrm{pH}$ and intermittent pulse exposure. Ecotoxicology and Environmental Safety 2020, 190, https://doi.org/10.1016/j.ecoenv.2019.109985

31. Sun, Y.; Cao, Y.; Tong, L.; Tao, F.; Wang, X.; Wu, H.; Wang, M. Exposure to prothioconazole induces developmental toxicity and cardiovascular effects on zebrafish embryo. Chemosphere 2020, 126418, https://doi.org/10.1016/j.chemosphere.2020.126418. 